\title{
Melanin Biosynthesis by Streptomyces lavendulae
}

\author{
By J. R. MENCHER ANd A. H. HEIM* \\ Department of Microbiology and Tropical Medicine, Schools of Medicine \\ and Dentistry, Georgetown University, Washington, D.C., U.S.A.
}

(Received 14, November 1961)

\begin{abstract}
SUMMARY
Streptomyces lavendulae was studied in a defined medium. When tyrosine was added to the medium a brown-black pigment was synthesized; without tyrosine, only a trace of this pigment was detected. Growth was the same with or without tyrosine. The addition of $\left(2-{ }^{14} \mathrm{C}\right)$ DL-tyrosine to the medium resulted in synthesis of a radioactive pigment, and tyrosinase activity was demonstrated in extracts of disrupted organisms. Of 15 amino acids added to the medium only tyrosine and tryptophan were used for pigment formation. Pigment production was inhibited by $p$ benzyloxy-phenol, an inhibitor of mammalian melanogenesis. In yeast + glucose medium a pH range of $6 \cdot 8-8 \cdot 2$ was optimal for pigment synthesis; more pigment was formed at $20^{\circ}$ than at $28^{\circ}$ in spite of the fact that there was twice as much growth at the latter temperature. The pigment was precipitated from culture media by a method described for precipitating melanin from urine and in every way tested was identical with a synthetic dihydroxyphenylalanine-melanin. The data indicate that the brown-black pigment synthesized by $\boldsymbol{S}$. lavendulae is melanin.
\end{abstract}

\section{INTRODUCTION}

Pigment synthesis by streptomycetes has aroused considerable interest for many years. The brown-black pigment has been referred to as 'melanin', and as 'melaninlike' because of demonstrations of an involvement of tyrosine in its synthesis. In this regard Skinner (1938) observed that pigmentation resulted from the addition of tyrosine to a defined medium upon which he was growing some actinomycetes and Douglas \& San Clemente (1956) observed a dark brown pigment in flasks in which mycelial homogenates of Streptomyces scabies were mixed with tyrosine, dihydroxyphenylalanine, or both. In attempting to correlate pigment formation and antibiotic synthesis by $S$. antibioticus Sevcik (1957) manometrically determined the presence of phenol oxidase activity, with tyrosine and several other substrates. While these studies suggest that the pigment is melanin, apparently no attempts have been made to isolate and characterize the pigment. Bergey's Manual (1957) refers to the pigment as a 'soluble brown pigment.'. The present paper reports an attempt to determine whether the brown-black pigment of $S$. lavendulae is actually melanin.

\section{METHODS}

Streptomyces lavendulae (no. 3515, Institute of Microbiology, Rutgers University, U.S.A.) was used throughout. Stock cultures of the organism were maintained on yeast+glucose agar, and yeast+glucose liquid medium was used as the seed

* Present address: Resources Research Inc., Washington, D.C., U.S.A. 
medium as well as for some preliminary observations. A defined medium (GGG) was used for most experiments. It contained (g.): glucose, 5.0; glycine, 10.0; monosodium glutamate, $10.0 ; \mathrm{K}_{2} \mathrm{HPO}_{4}, 0.5 ; \mathrm{MgSO}_{4} .7 \mathrm{H}_{2} \mathrm{O}, 0 \cdot 2 ;\left(\mathrm{mg}\right.$.): $\mathrm{CaCl}_{2} \cdot 2 \mathrm{H}_{2} \mathrm{O}$, $11 \cdot 0 ; \mathrm{FeSO}_{4} \cdot 7 \mathrm{H}_{2} \mathrm{O}, \mathbf{1 5} \cdot 0 ; \mathrm{ZnSO}_{4} \cdot 7 \mathrm{H}_{2} \mathrm{O}, \mathbf{1 3} \cdot 0 ; \mathrm{CuSO}_{4}, 7 \cdot 5$; distilled water to 1 litre. The medium without glucose (glucose autoclaved separately) was adjusted to about $\mathrm{pH} 7 \cdot 5$ and then autoclaved at $120^{\circ}$ for $15 \mathrm{~min}$. The medium after autoclaving and the addition of glucose was at $\mathrm{pH} 7 \cdot 2-7 \cdot 5$. Pigment formation was readily observed because the medium itself was colourless.

Each $100 \mathrm{ml}$. of medium in a $250 \mathrm{ml}$. Erlenmeyer flask was seeded with $\mathbf{2 . 0} \mathrm{ml}$. washed suspension of organism grown for 18-24 hr. in yeast + glucose liquid medium. Organisms used for inoculation of defined medium were washed by centrifugation and resuspension until two successive washings were colourless; usually four to five washings were adequate. Except for temperature studies, cultures were incubated at $28^{\circ}$ on a rotary shaker at $220 \mathrm{rev} . / \mathrm{min}$. and were routinely harvested by filtration after one week of incubation. Growth was determined as dry weight.

Relative values of pigment synthesis were obtained by determining $\%$ transmission of culture fluid at $540 \mathrm{~m} \mu$. using a Bausch and Lomb Spectronic 20 Colorimeter. The pigment was precipitated from culture fluids by a modification of a method described by Blackberg \& Wanger (1933) for precipitating melanin from urine. For this culture fluid was first adjusted to $\mathrm{pH} 7 \cdot 0$ and $1 \mathrm{~g}$. potassium persulphate was added for each $100 \mathrm{ml}$. of fluid and allowed to stand for $2 \mathrm{hr}$. with occasional shaking. Then $100 \mathrm{ml}$. of methanol was added for each $100 \mathrm{ml}$. of culture fluid and the mixture allowed to stand for 3 days; during this time pigment was precipitated, and was collected and washed by centrifugation. Pigment synthesized under various conditions was compared colorimetrically after dissolving the precipitated pigment in $10.0 \mathrm{ml} . \mathrm{M}-\mathrm{NaOH}$.

Synthetic DL-dihydroxyphenylalanine (dopa)-melanin was prepared by the method of Arnow (1938); $20 \mathrm{mg}$. of DL-dopa were dissolved in 50.0 ml. 0.01 $\mathrm{M}-\mathrm{NaOH}$ and aerated by bubbling air saturated with water through the solution for $1 \mathrm{hr}$. The resulting brown-black precipitate was collected and washed by centrifugation.

To prepare cell extracts, washed organism (equiv. about $1.0 \mathrm{~g}$. dry wt.) from an $18 \mathrm{hr}$. shake culture was suspended in 50.0 ml. 0.1 $\mathrm{M}$-phosphate buffer ( $\mathrm{pH} \mathrm{6.9)}$ and disrupted at maximum power in a $10 \mathrm{Kc}$ Raytheon sonic oscillator for $3 \mathrm{~min}$., whole organisms were separated from the suspension by centrifugation for $10 \mathrm{~min}$. Tyrosinase activity was determined by a method of Cooper \& Brown (1956) in which the cell extracts were added to holes cut in a phosphate-buffered agar plate containing tyrosine, dopa, or both together as substrates. Control plates were run without substrate. A positive reaction resulted in the formation around the hole of a pink ring which changed to brown and then black.

An inhibitor of melanogenesis, $p$-benzyloxy-phenol, was dissolved in methanol. Solutions were prepared on the day of use.

Radioactive pigment was assayed in a liquid scintillation spectrometer (Packard Tri-carb). 


\section{RESULTS}

\section{The effect of tyrosine on pigment biosynthesis in a defined medium}

To determine the effect of tyrosine on pigment synthesis by Streptomyces lavendulae various concentrations of tyrosine were tested in the defined medium described above. An increase in tyrosine concentration did not result in an increase or decrease in yield of organism nor did it have an effect on the $\mathrm{pH}$ value of the culture (Table 1). The principle effect of the tyrosine was on the amount of pigment synthesized: as the tyrosine concentration increased, the amount of pigment increased. To substantiate further the role of tyrosine in the formation of pigment, $\left(2{ }^{14} \mathrm{C}\right)$ DL-tyrosine was added to the defined medium, resulting in the synthesis of a radioactive pigment.

Table 1. Effect of tyrosine on pigment synthesis by Streptomyces lavendulae in a defined medium

\begin{tabular}{|c|c|c|c|}
\hline $\begin{array}{c}\text { Tyrosine } \\
\text { concentration } \\
\text { (g./l.) }\end{array}$ & $\begin{array}{c}\text { Resuspended } \\
\text { pigment } \\
(\% \text { transmission } \\
\text { at } 540 \mathrm{~m} \mu)^{*}\end{array}$ & $\begin{array}{c}\text { Yield of } \\
\text { organism } \\
\text { (mg. dry wt.)* }\end{array}$ & $\begin{array}{l}\mathrm{pH} \text { value } \\
\text { of culture }\end{array}$ \\
\hline $\begin{array}{l}\text { Control } \\
\text { (no tyrosine) }\end{array}$ & $\begin{array}{l}80 \\
83\end{array}$ & $\begin{array}{l}201 \\
165\end{array}$ & $\begin{array}{l}8 \cdot 4 \\
8 \cdot 3\end{array}$ \\
\hline $0 \cdot 1$ & $\begin{array}{l}76 \\
68\end{array}$ & $\begin{array}{l}152 \\
162\end{array}$ & $\begin{array}{l}8 \cdot 4 \\
8 \cdot 5\end{array}$ \\
\hline $0 \cdot 2$ & $\begin{array}{l}52 \\
52\end{array}$ & $\begin{array}{l}151 \\
171\end{array}$ & $\begin{array}{l}8 \cdot 5 \\
8 \cdot 5\end{array}$ \\
\hline $0 \cdot 3$ & $\begin{array}{l}39 \\
36\end{array}$ & $\begin{array}{l}147 \\
149\end{array}$ & $\begin{array}{l}8 \cdot 5 \\
8 \cdot 5\end{array}$ \\
\hline 0.4 & $\begin{array}{l}12 \\
16\end{array}$ & $\begin{array}{l}168 \\
166\end{array}$ & $\begin{array}{l}8 \cdot 5 \\
8 \cdot 5\end{array}$ \\
\hline
\end{tabular}

\section{Demonstration of tyrosinase activity}

The presence of a tyrosinase in Streptomyces lavendulae was shown by the tyrosinase assay described. At $20^{\circ}-\mathbf{2 4} 4^{\circ}$ the extract of sonically disrupted organisms began to oxidize dopa within $3 \mathrm{~min}$. as evidenced by the appearance of a pink ring around the extract-containing hole; this ring became dark brown to black within $1 \mathrm{hr}$. Autoxidation of dopa was not the cause of the colour change; if it were, the entire plate would have changed to the same colour. Tyrosine alone was oxidized by the extract but at a slower rate than dopa since the oxidation became apparent in $30 \mathrm{~min}$. Catalytic concentrations of dopa added to the tyrosine did not shorten this period. All controls were negative. At $37^{\circ}$ only dopa was oxidized by the extract. Removal of copper by adding sodium diethyldithiocarbamate to a system containing dopa + cell extract prevented a positive tyrosinase reaction.

\section{Inhibition of pigment biosynthesis}

$p$-Benzyloxy-phenol is an inhibitor of melanogenesis (Lerner \& Fitzpatrick, 1950 ; Peck \& Sobotka, 1941). To investigate the effect of this inhibitor on Streptomyces lavendulae different concentrations of it were added to a complete medium 
containing $0.3 \mathrm{~g}$. tyrosine/l. With increasing concentration of inhibitor there was a decrease in the amount of pigment synthesized (Table 2). However, cell synthesis appeared to be slightly stimulated by these concentrations of inhibitor. Concentrations of $1.0 \times 10^{-4} \mathrm{M}-p$-benzyloxy-phenol inhibited cell synthesis as well as pigment synthesis. The $\mathrm{pH}$ values were only slightly lower in the media containing $p$ benzyloxy-phenol. The effect of this compound was an inhibition of pigment synthesis without inhibition of cell synthesis.

Table 2. Inhibition of Streptomyces lavendulae pigment synthesis by p-benzyloxy-phenol in defined medium containing $0 \cdot 3$ g. tyrosine/l.

\begin{tabular}{|c|c|c|c|}
\hline $\begin{array}{c}p \text {-benzyloxy- } \\
\text { phenol } \times 10^{-5} M\end{array}$ & $\begin{array}{l}\text { Resuspended } \\
\text { pigment } \\
(\% \text { transmission } \\
\text { at } 540 \mathrm{~m} \mu)^{*}\end{array}$ & $\begin{array}{l}\text { Yield of } \\
\text { organisms } \\
\text { (mg. dry wt.)* }\end{array}$ & $\begin{array}{c}\text { pH value } \\
\text { of culturet }\end{array}$ \\
\hline $3 \cdot 0$ & $\begin{array}{l}94 \\
89\end{array}$ & $\begin{array}{l}190 \\
180\end{array}$ & $\begin{array}{l}8 \cdot 2 \\
8 \cdot 3\end{array}$ \\
\hline $2 \cdot 5$ & $\begin{array}{l}89 \\
81\end{array}$ & $\begin{array}{l}237 \\
204\end{array}$ & $\begin{array}{l}8 \cdot 3 \\
8 \cdot 5\end{array}$ \\
\hline $2 \cdot 0$ & $\begin{array}{l}91 \\
90\end{array}$ & $\begin{array}{l}205 \\
218\end{array}$ & $\begin{array}{l}8 \cdot 4 \\
8 \cdot 4\end{array}$ \\
\hline 1.5 & $\begin{array}{l}79 \\
85\end{array}$ & $\begin{array}{l}160 \\
175\end{array}$ & $\begin{array}{l}8 \cdot 4 \\
8 \cdot 6\end{array}$ \\
\hline $1 \cdot 0$ & $\begin{array}{l}72 \\
80\end{array}$ & $\begin{array}{l}160 \\
174\end{array}$ & $\begin{array}{l}8 \cdot 5 \\
8 \cdot 7\end{array}$ \\
\hline 0.5 & $\begin{array}{l}57 \\
56\end{array}$ & $\begin{array}{l}178 \\
178\end{array}$ & $\begin{array}{l}8 \cdot 4 \\
8 \cdot 5\end{array}$ \\
\hline Control Ał & $\begin{array}{l}60 \\
54\end{array}$ & $\begin{array}{l}107 \\
149\end{array}$ & $\begin{array}{l}8 \cdot 8 \\
8 \cdot 7\end{array}$ \\
\hline Control B & $\begin{array}{l}97 \\
94\end{array}$ & $\begin{array}{r}102 \\
95\end{array}$ & $\begin{array}{l}8 \cdot 9 \\
8 \cdot 9\end{array}$ \\
\hline \multicolumn{4}{|c|}{$\begin{array}{l}\text { * Values are those of duplicate flasks run at the same time. } \\
\dagger \text { Duplicate flasks; after incubation for } 1 \text { week at } 28^{\circ} \text {. } \\
\text { Control A: no } p \text {-benzyloxy-phenol. } \\
\text { Control B: no } p \text {-benzyloxy-phenol, no tyrosine. }\end{array}$} \\
\hline
\end{tabular}

Comparison of the pigment from Streptomyces lavendulae with a synthetic dopa-melanin

A comparison of the brown-black pigment synthesized by Streptomyces lavendulae and a sample of synthetic dopa-melanin showed them to be identical in several chemical and physical properties (Table 3). Their solubilities were the same, they reacted to oxidation and reduction in the same way, were precipitated by the same techniques, and neither exhibited any characteristic absorption peaks.

\section{Effect of amino acids other than tyrosine on pigment biosynthesis}

To examine the possibility that amino acids other than tyrosine have an effect on pigment biosynthesis by Streptomyces lavendulae, the following amino acids were added singly to the defined medium at $0.4 \mathrm{~g} . / 1$. : DL-alanine; L-arginine; DL-serine; DL-lysine monohydrochloride; DL-phenylalanine; sodium aspartate; L-histidine monohydrochloride; DL-leucine; L-proline; DL-threonine; DL-valine; L-tryptophan. 
Glycine and sodium glutamate were present as components of the synthetic medium. Of the fifteen amino acids tested only tyrosine and tryptophan were used for pigment synthesis. The pigment which resulted from tryptophan utilization was identical with the tyrosine pigment in all of the properties listed in Table 3. Phenylalanine, reported to be an inhibitor of melanogenesis (Lerner \& Case, 1959), actually stimulated pigment synthesis in the presence of tyrosine.

Table 3. Comparison of pigment of Streptomyces lavendulae with a synthetic dopa-melanin

Property

Solubility in water:

Solubility in $\mathrm{M}-\mathrm{NaOH}$ :

Colour:

Appearance in water:

Precipitation by Blackberg-

Wanger technique:

Precipitation from $\mathrm{NaOH}$ by $\mathrm{HCl}$

Formation of black precipitate with $\mathrm{FeCl}_{3}$ which dissolves with excess $\mathrm{FeCl}_{3}$

Reduction by sodium dithionite and re-oxidation by potassium ferricyanide

Absorption spectrum (350$650 \mathrm{~m} \mu$ )
Pigment of S. lavendulae

Insoluble

Soluble

Brown-black

Evenly dispersed floc

Precipitated

Precipitated

$+$

Black $\rightarrow$ tan

Tan $\rightarrow$ black

No characteristic peaks
Dopa-melanin

Insoluble

Soluble

Brown-black

Evenly dispersed floc

Precipitated

Precipitated

$+$

Black $\rightarrow$ tan

Tan $\rightarrow$ black

No characteristic peaks

The effect of $p H$ value and temperature on pigment biosynthesis

Yeast + glucose liquid medium adjusted to eleven different values from $\mathrm{pH} \mathbf{5 \cdot 2}$ to $8 \cdot 5$ was inoculated with Streptomyces lavendulae. The range $\mathrm{pH} 6 \cdot 8-8.2$ was most favourable for pigment synthesis. Yeast+glucose liquid medium seeded with $S$. lavendulae and incubated at $37^{\circ}, 28^{\circ}$ and $20^{\circ}$ yielded more pigment at $20^{\circ}$ than at $28^{\circ}$, in spite of the fact that there was only one half as much yield of organism. At $37^{\circ}$ the yield of organism was equal to that obtained at $20^{\circ}$, but only a trace of pigment could be detected.

\section{DISCUSSION}

The influence of tyrosine on pigment production by Streptomyces lavendulae is like melanin formation in other cells (Raper, 1927; Mason, 1948; Lerner, 1953). Although the disappearance of tyrosine from the medium was not followed it is probable that some tyrosine also was used for growth in spite of the fact that no net increase was observed in amount of organism dry weight. However, the tyrosine appeared to be preferentially utilized for pigment synthesis. A qualitative observation showed its incorporation into the pigment when $\left(2-{ }^{14} \mathrm{C}\right)$ DL-tyrosine was supplied in the medium. The utilization of tryptophan for pigment synthesis is not surprising because tryptophan is a precursor of kynurenine and anthranilic acid which can be metabolized to catechol. It is possible that melanin was synthesized by this route with catechol as substrate for tyrosinase. The tryptophan pigment had physical and chemical characteristics identical with the tyrosine pigment and with synthetic dopa-melanin. Conditions of synthesis, inhibition, and the physical and chemical 
characteristics of the precipitated pigment correspond to those known for dopamelanin. Because of these data it is submitted that the brown-black pigment of $S$. lavendulae is in fact melanin.

The authors wish to thank Dr Ruth E. Gordon, Institute of Microbiology, Rutgers University for the cultures of Streptomyces lavendulae. This investigation was supported in part by P.H.S. grant E-3119 for the National Institutes of Health, U.S.A.

One of the authors, J.R.M., was a trainee of U.S.P.H.S. Grant 2E-183.

\section{REFERENCES}

Arnow, L. E. (1938). Preparation of dopa-melanin. Science, 87, 308.

Blackberg, S. N. \& Wanger, J. O. (1933). Melanuria. J. Amer. med. Ass. 100, 335.

COOPER, J. A. \& Brown, C. (1956). A rapid semi-quantitative method for the assay of tyrosinase activity. Clin. chem. Acta, 1, 301.

Douglas, R. J. \& San Cremente, C. L. (1956). Respiration of scab-producing strains of actinomycetes. Canad. J. Microbiol. 2, 407.

Lerner, A. B. (1953). Metabolism of phenylalanine and tyrosine. Advanc. Enzymol. 14, 73.

Lerner, A. B. \& CASe, J. D. (1959). Pigment cell regulatory factors. In Psoralens and Radiant Energy, a supplement to the Feb. 1959 issue of the J. invest. Derm. 32, no. 2.

Lerner, A. B. \& Fitzpatrick, T. B. (1950). Biochemistry of melanin formation. Physiol. Rev. 3, 91.

Mason, H. S. (1948). The chemistry of melanin. III. Mechanisms of the oxidation of dihydroxyphenylalanine by tyrosinase. J. biol. Chem. 172, 83.

Pеск, S. M. \& Sовотка, H. (1941). Effect of monobenzyl hydroquinone on oxidase systems in vivo and in vitro. J. invest. Derm. 4, 325.

RAPER, H. S. (1927). XIV. The tyrosinase-tyrosine reaction. Biochem. J. $21,89$.

Sevcik, V. (1957). Determination of phenol oxidase using a manometric method by Streptomyces antibioticus. Nature, Lond. 179, 966.

Skinner, C. E. (1938). The tyrosinase reaction of the actinomycetes. J. Bact. 35, 415. 